\title{
ARTICLE
}

\section{Occupational psychiatry in the armed forces: should depressed soldiers carry guns?}

\author{
Peter McAllister, Neil Greenberg \& Max Henderson
}

Peter McAllister is a Lieutenant Colonel with the Royal Army Medical Corps, and the consultant advisor in psychiatry to the Director General Army Medical Services. His interests include the impact of operational deployments on mental health. Neil Greenberg is Surgeon Commander and Defence Professor of Mental Health at King's College London, and is also a military consultant psychiatrist in the Royal Navy. He has a keen interest in organisational mental health, traumatic stress and the psychological health of military personnel. Max Henderson is a senior lecturer in epidemiological and occupational psychiatry at the Institute of Psychiatry, London.

$\mathrm{He}$ is a liaison psychiatrist with a clinical and research interest in the relationship between work and mental health. He is currently researching the impact of individual life-course risk factors on long-term sickness absence.

Correspondence DrPeter McAllister, Consultant Advisor in Psychiatry to Director General Army Medical Services, DCMH Tidworth, Wiltshire SP9 7EA, UK. Email: peter. mcallister404@mod.uk

\begin{abstract}
SUMMARY
The Defence Mental Health Services (DMHS) provide an occupationally focused service for the UK armed forces when deployed and when at home. Although much of the work is similar to that carried out by National Health Service community mental health teams, there are many unique aspects to working with the military. Although carrying out operational duties is a key function of the armed forces, the majority of cases managed by the DMHS are not related to traumatic exposures; instead, adjustment, mood and substance use disorders form the bulk of the case work. However, DMHS personnel carry out a considerable amount of psychological education and command liaison functions to support the concept that the psychological welfare of troops is primarily a chain of command responsibility. This article outlines the structure and function of the DMHS and its approach to risk management.
\end{abstract}

\section{DECLARATION OF INTEREST}

P.M. and N.G. are serving regular officers in the DMHS. This article has been seen and approved by the Ministry of Defence; no substantial changes to the content of this article were mandated.

\section{'The patient is the Army, not the individual.' Major Dugmore Hunter (1944)}

The relationship between an individual's occupation and their mental health is becoming increasingly important in National Health Service (NHS) practice. Managing this interaction is precisely what the Defence Mental Health Services (DMHS) specialise in. Decisions are made, on a daily basis, about the impact of mental health on occupational function, and DMHS clinicians regularly consider which occupational restrictions must be put in place to protect a patient's mental health and preserve the fighting force.

The high intensity of recent military operations in both Iraq and Afghanistan means that there is likely to be a steady flow of veterans with operational experience returning to the care of the NHS. This article aims to inform receiving clinicians about the level of care that may have been available to military personnel while they were still serving and to highlight what sources of care provision are available to military veterans.

The principles of military psychiatry are closely aligned to those of occupational medicine; that is, to provide 'health advice to organisations and individuals to ensure that the highest standards of health and safety at work can be achieved and maintained' (Faculty of Occupational Medicine 2004). The 'work' of the armed forces is highly varied and at times almost unique, for example, the use of potentially lethal force in the pursuit of national interests. Military psychiatrists work as part of the DMHS and, like other military physicians, they aim to 'maximise the potential of our people through the provision of excellent health services for the defence population at risk' (Ministry of Defence 2007).

As is the case for other occupationally focused specialties, a successful military psychiatry service must balance the needs of the individual soldier and those of the organisation. This involves clinicians exercising judgement based on both their psychiatric knowledge and their military experience. Not uncommonly, decisionmaking has an ethical dimension to it: being fit for one's role in the military is inherently risky and when fit from a psychological viewpoint, service personnel may well be ready to deploy to areas where their physical health, and indeed their life, may be at risk.

This article begins by outlining the current structure of the UK armed forces, goes on to explain the varied roles of the DMHS and ends by describing how healthcare provision for still serving personnel and veterans is organised.

\section{Structure of the DMHS}

The DMHS provide military personnel with timely access to skilled and effective psychological support - and where necessary, treatment - in a flexible and occupationally focused manner. Military mental health professionals aim to foster recovery and rehabilitation, ensuring that 
wherever possible service personnel either return to duty or are supported as they successfully move back into civilian life. The DMHS aim to provide high-quality mental healthcare to those that need it, as locally to an individual's military unit as is possible. A clear understanding of the military, including ethos and roles, underpins the successful delivery of mental healthcare to service populations. The delivery of this care is multidisciplinary, provided by both uniformed and civilian professionals.

\section{Chain of command}

Within the UK armed forces the psychological welfare of troops is primarily a chain of command (effectively a 'line management') responsibility. 'Physical' matters such as hydration management are managed in the same way as 'psychological' issues. Both may benefit from a subject matter expert providing appropriate information and training; however, the subject matter expert is not routinely responsible for the health of personnel unless they become unwell.

Where the chain of command is unable to provide appropriate support, personnel are able to access a three-tiered structure: primary care, community mental healthcare and, where needed, in-patient care. The last military in-patient facility in the UK closed in 2004 and currently all in-patient care is provided through a contract with a lead provider (South Staffordshire and Shropshire NHS Foundation Trusts), which leads a network of eight other trusts UK wide, ensuring that the armed forces have access to regional in-patient facilities across the country. Military treatment protocols advocate using in-patient care for the minimum amount of time possible. The principle of providing mental healthcare close to the workplace is seen as the key to effective occupational rehabilitation by the DMHS.

\section{Departments of community mental health}

Departments of community mental health (DCMHs) carry out all specialist mental health functions within the DMHS. There are 15 such departments in the UK, with further units in Germany, Cyprus and Gibraltar. They provide service personnel with a range of mental health educational programmes, liaise with independent service providers and facilitate discharges where appropriate. They are manned by about 150200 military mental health professionals. Most $(\sim 75 \%)$ are nurses, with the remainder being psychiatrists, clinical psychologists and social workers. Nursing and psychiatric specialists are drawn from uniformed personnel; all social work and psychology staff are civil servants. Presently, occupational therapists do not form part of the DCMH team, other than in Germany, which is a legacy from there having been a psychiatric inpatient unit based in Germany.

The DMHS staff currently provide care for all regular service personnel in the UK and on operations. Care is extended to families and other entitled staff (such as Ministry of Defence civilians, e.g. teachers, shopkeepers) when working in Germany.

In addition to their clinical work, military psychiatrists liaise with the admitting consultants for the in-patient service and provide teaching for both medical staff and commanders at all levels. Mental health research is coordinated and frequently undertaken by the Academic Centre for Defence Mental Health based at King's College London.

\section{Reserves' Mental Health Programme}

In the main, mental health services for military veterans remain the responsibility of the NHS. However, supported by research carried out at King's College London into the health of service personnel deployed to the 2003 Iraq War, which found higher rates of mental health problems in reservists (Hotopf 2006), the Ministry of Defence set up the Reserves' Mental Health Programme (RMHP). The RMHP is based at the Reserves Mobilisation and Training Centre in Chilwell, and entitles reservists who have deployed overseas on an operational tour since January 2003, who attribute their mental health difficulties to an operational deployment, to be assessed by a military mental health provider. Those found to have a mental heath disorder attributable to their deployment are entitled to care at a military department of community mental health.

\section{Medical Assessment Programme}

However, what of demobilised regular service members? The Medical Assessment Programme, based at St Thomas' Hospital, London, was set up to investigate veterans of the 1991 Gulf War, who attributed their symptoms to their deployment. Over recent years, the Medical Assessment Programme has been enhanced to address the needs of any service personnel who may have service-related illness as a result of operations conducted since 1982. Unlike the RMHP, which can refer to departments of community mental health, the Medical Assessment Programme can only refer on to local NHS facilities. Several pilots of NHS veteran community mental healthcare (Box 1) have now been evaluated and the results 
BOX 1 Contact details of the six pilots of the enhanced NHS services for UK military veterans
South Stafford and Shropshire Healthcare NHS Foundation Trust Coton House, St George's Hospital Site, Corporation Street, Stafford ST16 3AG. Tel: 01785257888 ext 5280

Community Veterans' Mental Health Assessment Service

Traumatic Stress Clinic, 73 Charlotte Street, London W1T 4PL. Tel: 0207530 3666; email: veterans@candi.nhs.uk; website: www. candi.nhs.uk/veterans

NHS Bishop Auckland General Hospital The Tees, Esk and Wear Valleys NHS Foundation Trust, Psychological Therapy Service, St Aidans House, St Aidans Walk, Bishop Auckland, County Durham DL14 6SA. Tel: 01388646 802; email: symon.day@ TEWV.nhs.uk
Cardiff and Vale NHS Trust Neil Kitchiner - CV MHT, University Hospital of Wales, Heath Park, Cardiff CF14 4XW. Tel: 0292074 2284; email: neil.kitchiner@ cardiffandvale.wales.nhs.uk; website: www. veterans-mhs-cvct.org/

Community Veterans Mental Health Service

Trevillis House, Lodge Hill, Liskeard, Cornwall PL14 4NE. Tel: 01579 335226; email:Veteran.Assistance@cornwall.nhs.uk

\section{Veterans First Point}

NHS Lothian Traumatic Stress Centre, 5th Floor, Charlotte House, 2 South Charlotte Street, Edinburgh EH2 4AW. Tel: 0131220 9920; enquiries@veteransfirstpoint.org.uk; website: www.veteransfirstpoint.org.uk are being used by the Department of Health to inform implementation of Murrison's (2010) recommendations for veteran support.

\section{The nature of military patients}

The patient characteristics and spectrum of mental health disorders seen by military psychiatrists can be quite different from those seen in civilian psychiatric practice. First, no one is under 16 years of age and very few are over 60. Also, although $7 \%$ of the UK population are aged $18-24$, some $30 \%$ of the army are so. Second, although as an equal opportunities employer the military has increased the proportion of female staff, the armed forces remain a male-dominated environment: less than 10\% are female (Defence Analytical Services and Advice 2010: Table 2.7). Also, women are still excluded from serving in a front-line ground combat role, although in recent conflicts the conventional concept of a 'front line' rarely applies, and female personnel can come under attack and be expected to respond. Despite these differences, the actual psychiatric disorders seen in military practice are similar to those seen in other occupational settings. Neurotic disorders are most frequently seen, with schizophrenia and other psychoses relatively rare (Table 1).

All three services (Royal Navy, British army and Royal Air Force) employ occupational physicians to manage the corporate health of the organisation. Military psychiatrists often work alongside them and advise on mental health issues and carry out joint assessments at formal medical boards which decide on personnel's longer-term employability. Deciding on an individual's fitness, including whether they are fit to deploy and handle weapons, is complex, and to ease the communication of such health data, the services use a grading system (Table 2) that distinguishes full fitness from temporary limitations, permanent limitations and conditions not conducive to ongoing service.

TABLE 1 Initial mental disorder assessments in 2010: ICD-10 groupings by deployment

\begin{tabular}{|c|c|c|c|c|c|c|c|c|c|c|c|}
\hline \multirow[b]{3}{*}{ ICD-10 description } & \multirow[b]{3}{*}{$\begin{array}{c}\text { All patients, } \\
N(\%)\end{array}$} & \multicolumn{10}{|c|}{ Deployment: theatres of operation } \\
\hline & & \multicolumn{3}{|c|}{ Iraq and/or Afghanistan ${ }^{a}$} & \multicolumn{3}{|c|}{ Iraq } & \multicolumn{3}{|c|}{ Afghanistan } & \multirow{2}{*}{$\begin{array}{c}\text { Neither } \\
\text { Patients, } \\
n(\%)\end{array}$} \\
\hline & & $\begin{array}{c}\text { Patients, } \\
n(\%)\end{array}$ & $\mathbf{R R}$ & $(95 \% \mathrm{CI})$ & $\begin{array}{c}\text { Patients, } \\
n(\%)\end{array}$ & $\mathbf{R R}$ & $(95 \% \mathrm{CI})$ & $\begin{array}{c}\text { Patients, } \\
n(\%)\end{array}$ & $\mathbf{R R}$ & $(95 \% \mathrm{CI})$ & \\
\hline All patients seen & 5581 & 3287 & & & 2218 & & & 2050 & & & 2294 \\
\hline $\begin{array}{l}\text { All patients assessed with a } \\
\text { mental disorder }\end{array}$ & $3942(70.6)$ & $2495(75.9)$ & 1.1 & $(1.0-1.2)$ & $1682(75.8)$ & 1.0 & $(1.0-1.1)$ & $1582(77.2)$ & 1.2 & $(1.1-1.3)$ & $1447(63.1)$ \\
\hline Psychoactive substance use & $309(5.5)$ & $184(5.6)$ & 1.0 & $(0.8-1.2)$ & $126(5.7)$ & 0.9 & $(0.7-1.2)$ & $113(5.5)$ & 1.0 & $(0.8-1.3)$ & $125(5.5)$ \\
\hline Disorders due to alcohol & $293(5.3)$ & $175(5.3)$ & 1.0 & $(0.8-1.2)$ & $123(5.3)$ & 0.9 & $(0.7-1.2)$ & $104(5.1)$ & 1.0 & $(0.7-1.2)$ & $118(5.1)$ \\
\hline Mood disorders & $901(16.6)$ & $526(16.0)$ & 0.9 & $(0.8-1.0)$ & $394(17.8)$ & 0.9 & $(0.8-1.1)$ & $279(13.6)$ & 0.8 & $(0.7-0.9)$ & $375(16.4)$ \\
\hline Depressive episode & $835(15.0)$ & $489(14.9)$ & 0.9 & $(0.8-1.0)$ & $364(16.4)$ & 0.9 & $(0.8-1.1)$ & $262(12.8)$ & 0.8 & $(0.7-1.0)$ & $346(15.1)$ \\
\hline Neurotic disorders & $2443(43.8)$ & $1632(49.7)$ & 1.3 & $(1.2-1.4)$ & $1053(47.5)$ & 1.2 & $(1.1-1.3)$ & $1096(53.5)$ & 1.5 & $(1.3-1.6)$ & $811(35.4)$ \\
\hline Post-traumatic stress disorder & $249(4.5)$ & $214(6.5)$ & 4.0 & $(2.8-5.7)$ & $114(5.1)$ & 2.9 & $(2.0-4.2)$ & $178(8.7)$ & 5.5 & $(3.8-7.9)$ & $35(1.5)$ \\
\hline Adjustment disorder & $1568(28.1)$ & $1038(31.6)$ & 1.3 & $(1.1-1.4)$ & $663(29.9)$ & 1.1 & $(1.0-1.3)$ & $706(34.4)$ & 1.4 & $(1.3-1.6)$ & $530(23.1)$ \\
\hline $\begin{array}{l}\text { Other mental and behavioural } \\
\text { disorders }\end{array}$ & $289(5.2)$ & $153(4.7)$ & 0.7 & $(0.6-0.9)$ & $109(4.9)$ & 0.7 & $(0.6-0.9)$ & $94(4.6)$ & 0.7 & $(0.6-1.0)$ & $136(5.9)$ \\
\hline No mental disorder & $1639(29.4)$ & $792(24.1)$ & & & $536(24.2)$ & & & $468(22.8)$ & & & $847(36.9)$ \\
\hline
\end{tabular}

$\mathrm{RR}$, rate ratio. Rates are per 1000 strength.

a. Does not include personnel deployed to Afghanistan during the period January 2003 to October 2005.

Source: Defence Analytical Services and Advice 2011 
TABLE 2 Medical grading restrictions

\begin{tabular}{|lllc|}
\hline Code & Definition & Restrictions & P-grading \\
\hline MFD & $\begin{array}{l}\text { Medically fully } \\
\text { deployable }\end{array}$ & No restrictions & P2 \\
\hline MLD & $\begin{array}{l}\text { Medically limited } \\
\text { deployability }\end{array}$ & $\begin{array}{l}\text { May be restricted } \\
\text { to main bases or } \\
\text { specific locations }\end{array}$ & P3 \\
\hline MND & $\begin{array}{l}\text { Medically non- } \\
\text { deployable }\end{array}$ & $\begin{array}{l}\text { Not fit to deploy } \\
\text { on operations }\end{array}$ & P7 \\
\hline 0 & $\begin{array}{l}\text { Under medical } \\
\text { board review }\end{array}$ & $\begin{array}{l}\text { Unfit all duties, } \\
\text { pending } \\
\text { occupational } \\
\text { medicine review }\end{array}$ & P0 \\
\hline
\end{tabular}

\section{Weapon handling}

Even with the recent well-publicised increase in operational tempo (Rona 2007), the vast majority of the armed forces does not have regular access to weapons. Nevertheless, all personnel are subject to an annual personal weapons test, which is carried out while heeding stringent safety precautions. Advances in technology mean that individuals can shoot at a video of a firing range, much like a computer game, which can simulate a wide array of potential conflict situations (e.g. jungle or desert patrolling). The video range can also be used as a 'judgemental trainer', testing an individual's responses to a situation played out on the video screen. Such training helps to clarify the current Rules of Engagement, which are taught to all service personnel and cover the legal and illegal use of lethal force on operations.

\section{Suicide standardised mortality ratio}

Although the standardised mortality ratio (SMR) from suicide is generally much lower in the armed forces than in the general population (Fear 2009), the increased suicide rate among young men in the army has made access to weapons an important issue. Official statistics show that suicide rates are highest among army personnel below the age of 21 compared with both older army personnel and personnel from the other two services (Table 3). The same statistics suggest that some of this increase in risk may be related to access to weapons; however, two modes of suicide are more common in all three groups of the armed forces than among the civilian population - hanging and suffocation. Other studies on military veterans have shown that the increased risk of suicide does not decline for those who leave early, but does so for those who stay in service (Kapur 2009), suggesting that the increased risk is most probably related to background risk factors which originate before personnel join up.

\section{Risk management}

Risk-taking is part of military service, but this does not lessen the tragedy when service personnel take their own lives. The risk a patient, given their access to weapons, may pose to themselves or their colleagues needs to be balanced with the potential risk to themselves or their colleagues of not having a weapon when deployed in a hostile environment. Military psychiatrists must also consider theimpact a suicide might have on the reputation and morale of the armed forces. Currently, society appears reluctant to accept anything but the lowest level of casualties in conflicts overseas, lower still from suicide. Also to be taken into consideration is both the actual and subjective impact on a serviceman's career that having psychiatric restrictions placed on their employability, including possibly losing access to weapons, even for a comparatively short time, can have. However, the management of

TABLE 3 Number of suicides, standardised mortality ratios (SMRs) and age-specific mortality ratios by service and age group, males, 1984-2007

\begin{tabular}{|c|c|c|c|c|c|c|c|c|c|c|c|c|}
\hline \multirow[b]{2}{*}{ Age group, years } & \multicolumn{3}{|c|}{ All } & \multicolumn{3}{|c|}{ Royal Navy } & \multicolumn{3}{|c|}{ British army } & \multicolumn{3}{|c|}{ Royal Air Force } \\
\hline & $n(\%)$ & SMR & (95\% CI) & $n(\%)$ & SMR & $(95 \% \mathrm{CI})$ & $n(\%)$ & SMR & $(95 \% \mathrm{CI})$ & $n(\%)$ & SMR & (95\% CI) \\
\hline All & 694 & 58 & (54-63) & 117 & 47 & $(39-56)$ & 421 & 70 & $(64-77)$ & 156 & 46 & $(39-54)$ \\
\hline$<20$ & $81(11.7)$ & 124 & $(100-155)$ & $7(6.0)$ & 63 & $(25-129)$ & $68(16.2)$ & 150 & (118-190) & $6(3.9)$ & 69 & $(25-150)$ \\
\hline $20-24$ & $214(30.8)$ & 71 & $(62-81)$ & $29(24.8)$ & 48 & $(32-70)$ & $153(36.3)$ & 87 & $(75-102)$ & $32(20.5)$ & 47 & $(34-67)$ \\
\hline $25-29$ & $147(21.2)$ & 52 & $(44-61)$ & $23(19.7)$ & 39 & $(25-59)$ & $83(19.7)$ & 57 & $(46-70)$ & $41(26.2)$ & 52 & $(38-70)$ \\
\hline $30-34$ & $104(15.0)$ & 49 & $(40-59)$ & $22(18.8)$ & 46 & $(29-69)$ & $50(11.9)$ & 49 & $(37-65)$ & $32(20.5)$ & 50 & $(35-70)$ \\
\hline $35-39$ & $87(12.5)$ & 50 & $(40-61)$ & $24(20.5)$ & 57 & $(37-85)$ & $43(10.2)$ & 55 & $(40-74)$ & $20(12.8)$ & 37 & $(22-56)$ \\
\hline $40-44$ & $42(6.1)$ & 51 & (37-68) & $8(6.8)$ & 43 & $(19-85)$ & $16(3.8)$ & 52 & $(30-85)$ & $18(11.5)$ & 53 & $(31-84)$ \\
\hline $45-49$ & $16(2.3)$ & 39 & $(22-63)$ & $4(3.4)$ & 42 & $(11-107)$ & $8(1.9)$ & 59 & $(26-117)$ & $4(2.6)$ & 22 & $(6-56)$ \\
\hline $50+$ & $3(0.4)$ & 13 & (3-38) & 0 & 0 & - & 0 & 0 & - & $3(1.9)$ & 29 & $(6-83)$ \\
\hline
\end{tabular}

Source: Defence Analytical Services Agency 2008. 
such risks in barracks is straightforward, as only a small number of troops require limited access to weapons (e.g. military guard staff for a period of guard duty), and the remainder of the force do not have regular access to weapons and live ammunition.

There is no self-certification for sickness absence in the armed forces. Personnel are required to present to their military medical officer to be granted a period of sick leave, even for a day off because of a viral illness. The high level of scrutiny the armed forces receive in relation to their physical health extends to their mental health, and primary care providers are substantially more likely to refer patients on for a mental health assessment than is the case in the NHS. The current standard for access to a mental health assessment is within $24 \mathrm{~h}$ for urgent cases, while routine cases are offered an appointment within 20 working days. In addition to granting temporary sick leave, the primary care physician can enforce occupational restrictions such as light duties, excused battle physical training, excused wearing boots, excused shaving, but most importantly in terms of risk with firearms, can restrict access to weapons and ammunition. Such restricted weapons access is commonly put in place by general practitioners as an additional precaution, notwithstanding the low level of weapon handling in a peace-time barracks.

Training establishments are especially riskaware environments, partly because of the higher levels of suicide among the youngest soldiers and partly because of the requirement for frequent use of weapons by novices during the initial training, compared with the mandatory annual updates for trained personnel. Furthermore, training of recruits has to be realistic and is therefore arduous, which adds to the pressure experienced by trainees. While deployed on operations, the requirement to bear arms is much greater than when in barracks. Depending on the current threat level, personnel may be required to carry arms at all times, or simply when leaving a secure base. This can include members of the field mental health team (McAllister 2004). At times of high threat, an individual unable to bear arms must be removed from the theatre of operations.

While troops are on deployment, operational requirements require the prime aim of the DMHS to shift, briefly, from the care of the individual to the maintenance of fighting capability. The principles of PIES (proximity, immediacy, expectancy and simplicity: Box 2) are employed both to maximise operational capability and to limit stigma and offer a better long-term outcome for psychiatric casualties (Solomon 1986). When
BOX 2 The 'PIES' principles for treating psychiatric casualties

- Proximity (being treated close to the location of trauma, with minimal evacuation)

- Immediacy (being treated as soon after the trauma as possible)

- Expectancy (the clear expectation of all concerned that return to unit in theatre will be the outcome in the vast majority of cases)

- Simplicity (desirable in the chaos of war)

(Scott 2005)

psychiatric casualty evacuation (CASEVAC) is required, patients can be rapidly and efficiently repatriated for in-patient care in the UK or Germany. However, it is worth remembering that the military encourages a high level of peer support, and the majority of armed forces personnel will, in the first instance, rely heavily on their colleagues for their emotional needs rather than relying on medical or welfare services (Greenberg 2003). The military also makes use of a non-medical peer support programme called Trauma Risk Management (TRiM) and military psychiatrists both teach on the TRiM courses and supervise the TRiM practitioners as they support their peers (Gould 2007).

\section{Current guidance}

Each of the three services has similar ways of managing the issues of deployment, access to weapons and mental health. Someone who is floridly unwell will be considered unfit for both deployment and access to firearms. However, if a service member is symptom free but requires maintenance therapy, this is dealt with differently by each service. The army's current guidance is less prescriptive than that of the Royal Navy or the Royal Air Force.

\section{Downgrading}

The majority of 'downgradings' are organised within primary care, with advice from mental health teams based at the DCMHs. Those who have a mental illness will have appropriate levels of restrictions on their employability put in place, for example 'P7 S7R', which indicates that they are medically not deployable and will, most likely, have their access to weapons restricted. This reflects the principle that any service member who is acutely ill needs occupational restrictions for their own and others' safety. 
As the mental health condition improves, this can be indicated in their medical downgrading, with a change from P7 to P3, reflecting 'vulnerability' rather than an 'acute illness'. Those who are downgraded to P3 will be considered to meet the medically limited deployable criteria and can be considered for deployment to major base areas only. These locations have access to well-staffed medical facilities, including the field mental health team, and have more assured supply chains for medication and easier rapid evacuation should the patient relapse. The decision to allow a previously unwell service member to deploy as part of an occupational rehabilitation process is made jointly between the psychiatrist and the primary care physician. On occasion, even when an individual expresses a desire to deploy, the primary care physician may hesitate about allowing this and can override a psychiatrist's medical recommendation. However, decisions on an individual's deployability are usually taken jointly in consultation with the patient and, within the limits of medical confidentiality, with the chain of command.

\section{New initiatives}

Although this article focuses on the delivery of mental healthcare to the serving military, over the years there have been numerous concerns expressed about the psychological health needs of military veterans; that is, those who are no longer serving and therefore no longer entitled to the bespoke and culturally specific occupational care provided. Although the available evidence suggests that, on the whole, the majority of military veterans do well, from a psychological viewpoint, once they leave, both the Ministry of Defence and NHS have recognised that there may be some cultural difficulties which act as a barrier that prevents some veterans from seeking help (Iversen 2009). As mentioned earlier, the six mental health pilot schemes established around the UK to provide enhanced mental healthcare for veterans (Box 1) have now been evaluated for the Department of Health. It is to be hoped that they represent a viable mechanism to ensure that veterans are able to access NHS care, on a priority basis, for conditions that may be related to their military service.

\section{Conclusions}

A core function of an occupational mental health service is to balance the needs of the individual with those of the employing organisation. At times, these two will be in concert, often with the desires of both parties being in unison; however,
B0X 3 Key points

- There is a uniformed, occupationally focused menta health service within the armed forces

- Routine access to weapons is rare, other than on deployment

- The standardised mortality rate (SMR) for suicide is substantially lower among service personnel than among the general population

- An exception to this is men in the army under 21 years old, for whom the SMR is about $50 \%$ higher than that for the gender- and aged-matched general population

- There is a medical grading system that reflects both vulnerability and active illness; this grading system allows occupational restrictions to be enforced

- The efforts made by the Defence Mental Health Service to reduce stigma, detect and treat illness, and place occupational restrictions on its staff, for their safety and the safety of others, may offer a model of management for other high-risk employment groups (e.g. drivers, machine operators, those for whom impaired function can have significant impact)

it is when they are in conflict that a military psychiatrist's skills and judgement are challenged. Although the safest course of action would be to restrict everyone's access to weapons and never deploy on operations, acting in such a risk-averse manner would have an immense impact on the armed forces' ability to carry out their main role.

Although the media frequently comment on the psychological health of military personnel the role of the DMHS in maintaining the operational capability of the UK armed forces is often unstated (Box 3). Given the current emphasis of the National Institute for Health and Clinical Excellence on the management of common mental health disorders such as post-traumatic stress disorder, which is the main effort of the DMHS, it may be that military mental health professionals will find themselves with a more central role in the years ahead and be a resource to assist their NHS colleagues in adopting a more occupationally focused approach to treatment.

\section{References}

Defence Analytical Services Agency (2008) Suicide and Open Verdict Deaths in the UK Regular Armed Forces 1984-2007. DASA (www.dasa. mod.uk/modintranet/publications/pdfs/suicide/suicideMar08.pdf).

Defence Analytical Services and Advice (2010) Personnel. In UK Defence Statistics 2010. DASA (http://www.dasa.mod.uk/modintranet/UKDS/ UKDS2010/c2/table207.php).

Defence Analytical Services and Advice (2011) UK Armed Forces Mental Health: Annual Summary 2010. DASA (http://www.dasa.mod.uk/ applications/newWeb/www/index.php?page=48\&pubType=0\&thiscont ent $=1290 \&$ PublishTime $=09: 30: 00 \&$ date $=2011-05-04 \&$ disText $=2010 \% 20$ Summary\&from=listing\&topDate=2010-05-04)
MCO answers

1 b 2 c 3 d 4 b 5 e 
Faculty of Occupational Medicine (2004) What is occupational medicine? Royal College of Medicine (http://www.facoccmed.ac.uk/about/ whatsom.jsp).

Fear NT, Ward VR, Harrison K, et al (2009) Suicide among male regular UK armed forces personnel, 1984-2007. Occupational and Environmental Medicine 66: 438-41.

Gould M, Greenberg N, Hetherton J (2007) Stigma and the military: evaluation of a PTSD psycho educational program. Journal of Trauma and Stress 20: 505-15.

Greenberg N, Thomas S, Iversen A, et al (2003) Do military peacekeepers want to talk about their experiences? Perceived psychological support of UK military peacekeepers on return from deployment. Journal of Mental Health 12: 561-9.

Hotopf M, Hull L, Fear N, et al (2006) The health of UK military personnel who deployed to the 2003 Iraq War: a cohort study. Lancet 367: $1731-41$.

Iversen AC, Greenberg N (2009) Mental health of regular and reserve military veterans. Advances in Psychiatric Treatment 15: 100-6.
Kapur N, While D, Blatchley N, et al (2009) Suicide after leaving the UK armed forces - a cohort study. PLoS Medicine 6: e10000026.

McAllister PD, Blair SPR, Philpott S (2004) Op Telic - a field mental health team in the general support medical setting. Journal of the Royal Army Medical Corps 150: 107-12.

Ministry of Defence, Defence Medical Services Department (2007) Defence Health Programme 2007-2011. MoD.

Murrison A (2010) Fighting Fit: A Mental Health Plan for Servicemen and Veterans. Department of Health.

Rona RJ, Fear NT, Hull L, et al (2007) Mental health consequences of overstretch in the UK armed forces: first phase of a cohort study. BMJ 335: 603.

Scott JN (2005) Diagnosis and outcome of psychiatric referrals to the field mental health team, 202 Field Hospital, Op Telic I. Journal of the Royal Army Medical Corps 151: 95-100.

Solomon Z, Benbenishty R (1986) The role of proximity, immediacy and expectancy in frontline treatment of combat stress reactions amongst Israelis in the Lebanon War. American Journal of Psychiatry 143: 613-7.

\section{MCOs}

Select the single best option for each question stem

1 Causes of death in servicemen:

a enemy action is the most common cause of death in service personnel

b suicide rates are lower in the armed forces compared with the UK population

c suicide rates are the same across all three armed services

d gunshot wounds are the most common method of suicide in service personnel

e death by enemy action is more common than by road traffic accident.

2 The role of military psychiatrists:

a they never deploy with the troops

b they have no role in selecting recruits c they are involved in setting health standards for both entry and retention criteria

$d$ they only ever see serving personnel

$\mathrm{e}$ if they diagnose a mental health disorder in serving personnel, the individual is immediately discharged from the armed forces.

\section{Regarding current policy regarding access} to weapons:

a only a psychiatrist can make someone unfit to carry weapons

b most service personnel are armed when on duty

c mental health professionals are never required to carry weapons

$\mathrm{d}$ access to weapons is more common in the army than in the other two armed services

e personal weapon handling training is tested every 5 years.
4 Regarding provision of mental healthcare for veterans:

a there is no provision to assess the mental health needs of ex-servicemen

b military DCMHs have a role to play in treating demobilised reservist personnel

c the Medical Assessment Programme is only for veterans of the first Gulf War

$d$ the NHS has no responsibility for veterans

e care for veterans is exclusively carried out within the charitable sector.

5 The letters of the acronym PIES stand for: a exploratory

b indicated

c equality

d promptness

e simplicity. 